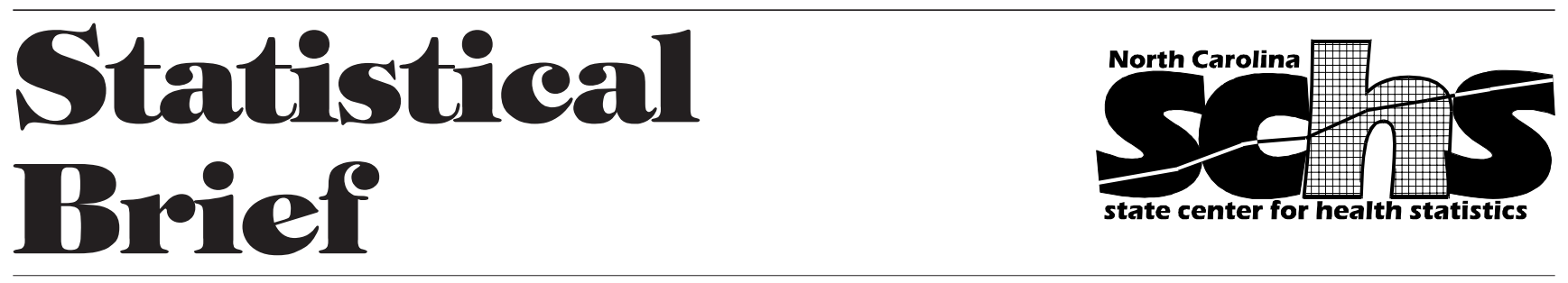

\title{
Maternal Smoking During Pregnancy and the Risk for Clubfoot in Infants: North Carolina, 1999-2003
}

\author{
by Kathryn C. Dickinson, Robert E. Meyer, and Jonathan B. Kotch*
}

\section{Introduction}

Talipes equinovarus, or clubfoot, is one of the most common major birth defects, with a prevalence of approximately 1 per 1,000 live births. ${ }^{1-3}$ Clubfoot affects males about twice as often as females. ${ }^{4-5}$ Infants born with clubfoot have abnormal foot bones, ankle bones, foot muscles and ligaments, and their heel cords are often tight, preventing the development of a normal gait. These malformations require medical treatment and often surgery for correction.

The causes of clubfoot are not well understood, although many have been proposed. A partial list of these causes include: intrauterine compression, vascular insufficiency, and neurologic abnormalities. ${ }^{6-8}$ Genetic and environmental factors are thought to play a role as well..$^{9-10}$ Maternal smoking during pregnancy is one environmental risk factor that has been studied with varying results, with findings ranging from a positively-correlated dose-response effect to a protective effect. ${ }^{11-12}$ This population-based case-control study aimed to further explore the link between maternal smoking during pregnancy and clubfoot in infants. It was hypothesized that maternal smoking during pregnancy would be associated with an increased risk of clubfoot being present in infants.

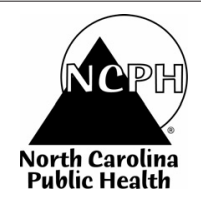

Statistical Brief No. 31

North Carolina

Department of Health and Human Services Division of Public Health

\section{Methods}

This study used data from the North Carolina Birth Defects Monitoring Program (NCBDMP) matched to the Composite Linked Birth File. The Composite Linked Birth File contains all North Carolina resident birth certificates linked to Medicaid paid claims and health department service data, such as the Special Supplemental Nutrition Program for Women, Infants, and Children (WIC) and maternity care coordination.

Infants born in 1999-2003 and diagnosed with clubfoot were ascertained by the NCBDMP. Cases included live-born, singleton infants with a diagnosis of either isolated (non-syndromic) talipes equinovarus or clubfoot not otherwise specified (British Pediatric Association codes 754.500 and 754.730). Non-isolated cases, which were excluded from the analysis, were those where there was also a major congenital anomaly in another organ system, or another major musculoskeletal defect not related to clubfoot, such as a limb reduction defect. After excluding the nonisolated cases (about 35\%) and those with missing maternal smoking data, a total of 443 cases were eligible for the study.

\footnotetext{
* Kathryn Dickinson and Robert Meyer are with the North Carolina Birth Defects Monitoring Program, State Center for Health Statistics. Jonathan Kotch is with the Department of Maternal and Child Health, UNC School of Public Health.
} 
Controls were obtained from North Carolina birth certificates and verified against the NCBDMP database to exclude infants with major birth defects. A simple random sample of 4,500 singleton births from the years 1999-2003 was generated. After excluding records with missing smoking data, there were 4,492 controls eligible for the study.

Smoking status was ascertained from the birth certificate (yes/no). In order to assess the reliability of smoking data on the birth certificate, North Carolina Pregnancy Risk Assessment Monitoring System (PRAMS) survey data on self-reported maternal smoking were compared to smoking status as reported on the birth certificate for each PRAMS respondent for the years 19992003.

Other variables included in the analysis were maternal age, race/ethnicity, marital status, maternal education, parity (number of previous live births), Medicaid and WIC status, timing of prenatal care initiation, infant's sex, gestational age, birth weight, and infant death. Frequencies, unadjusted odds ratios, and adjusted odds ratios (using binary logistic regression) were computed.

\section{Results}

Comparing self-reported maternal smoking from PRAMS with smoking status as reported on the birth certificates for 1999-2003 indicated good agreement between the two sources. Approximately 95 percent of the 8,157 records were in concurrence $($ Kappa $=0.769)$.

Table 1 shows the descriptive statistics for both cases and controls. Case mothers were more likely to have

N.C. Department of Health and Human Services

\begin{tabular}{|c|c|c|c|c|}
\hline Maternal smoking & \multicolumn{2}{|c|}{$\begin{array}{c}\text { Cases } \\
n=443 \\
\text { number }(\%)^{*}\end{array}$} & \multicolumn{2}{|c|}{$\begin{array}{c}\text { Controls } \\
n=4,492 \\
\text { number }(\%)^{*}\end{array}$} \\
\hline Yes & 81 & (18.3) & 587 & $(13.1)$ \\
\hline No & 362 & (81.7) & 3905 & (86.9) \\
\hline \multicolumn{5}{|l|}{ Infant's sex } \\
\hline Male & 291 & $(65.7)$ & 2272 & $(50.6)$ \\
\hline Female & 152 & (34.3) & 2220 & (49.4) \\
\hline \multicolumn{5}{|l|}{ Maternal age } \\
\hline$<20$ & 61 & (13.8) & 501 & $(11.2)$ \\
\hline $20-24$ & 137 & (30.7) & 1258 & $(28.0)$ \\
\hline $25-29$ & 122 & (27.5) & 1223 & (27.3) \\
\hline$\geq 30$ & 124 & (28.0) & 1510 & (33.6) \\
\hline \multicolumn{5}{|l|}{ Maternal race/ethnicity } \\
\hline White, non-Hispanic & 302 & $(68.2)$ & 2728 & $(60.7)$ \\
\hline Black, non-Hispanic & 81 & (18.3) & 1075 & $(23.9)$ \\
\hline Hispanic & 49 & (11.1) & 527 & $(11.7)$ \\
\hline Other & 11 & (2.5) & 162 & (3.6) \\
\hline \multicolumn{5}{|l|}{ Maternal education } \\
\hline$<$ High School & 106 & (23.9) & 989 & $(22.0)$ \\
\hline High School & 144 & (32.5) & 1420 & $(31.6)$ \\
\hline$>$ High School & 187 & $(42.2)$ & 2068 & $(46.0)$ \\
\hline \multicolumn{5}{|l|}{ Marital status } \\
\hline Married & 283 & (63.9) & 2996 & $(66.7)$ \\
\hline Unmarried & 160 & (36.1) & 1495 & (33.3) \\
\hline \multicolumn{5}{|l|}{ Parity } \\
\hline 0 & 239 & $(54.0)$ & 1802 & $(40.1)$ \\
\hline $1-3$ & 194 & $(43.8)$ & 2551 & $(56.8)$ \\
\hline$>3$ & 10 & (2.3) & 138 & (3.1) \\
\hline \multicolumn{5}{|l|}{ Gestational age (in weeks) } \\
\hline$\leq 32$ & 10 & (2.3) & 83 & $(1.8)$ \\
\hline $33-36$ & 56 & (12.6) & 324 & $(7.2)$ \\
\hline$\geq 37$ & 377 & (85.1) & 4085 & $(90.9)$ \\
\hline \multicolumn{5}{|l|}{ Receipt of WIC } \\
\hline Yes & 197 & $(45.5)$ & 1674 & $(37.3)$ \\
\hline No & 246 & (55.5) & 2818 & $(62.7)$ \\
\hline \multicolumn{5}{|l|}{ Receipt of Medicaid } \\
\hline Yes & 100 & $(45.1)$ & 1792 & $(39.9)$ \\
\hline No & 243 & (54.9) & 2700 & $(60.1)$ \\
\hline \multicolumn{5}{|l|}{ Timing of prenatal care initiation } \\
\hline Adequate ( $1^{\text {st }}$ trimester $)$ & 415 & (93.7) & 4057 & $(90.3)$ \\
\hline Late (after $1^{\text {st }}$ trimester or none) & 25 & (5.6) & 414 & $(9.2)$ \\
\hline \multicolumn{5}{|l|}{ Infant death } \\
\hline Yes & 2 & $(0.5)$ & 29 & $(0.6)$ \\
\hline No & 441 & $(99.5)$ & 4463 & $(99.4)$ \\
\hline
\end{tabular}


smoked during pregnancy, with 18.3 percent reporting they did so compared to 13.1 percent of control mothers. Case infants were more likely to be male than control infants $(65.7 \%$ vs. $50.6 \%)$. Control mothers were less likely to be nonHispanic white and also less likely to be primiparous compared to case mothers. Examining the relationship between smoking and clubfoot indicated that women who smoked during pregnancy were about 50 percent more likely to deliver an infant with clubfoot compared to women who did not smoke (unadjusted odds ratio $(\mathrm{OR})=1.49 ; 95 \%$ confidence interval $(\mathrm{CI})=1.15$ 1.92). After adjusting for sex of the infant, maternal age, race/ethnicity, and the timing of prenatal care initiation, the odds ratio did not change appreciably (adjusted OR $=1.40,95 \% \mathrm{CI}$ $=1.07-1.83$ ) (Table 2). Also shown in Table 2, male infants were almost twice as likely to have clubfoot than female infants, increasing maternal age was associated with a slightly reduced risk of having a baby with clubfoot, and non-Hispanic black women were about one-third less likely to have a baby with clubfoot than their non-Hispanic white counterparts.

\begin{tabular}{|c|c|}
\hline & OR (95\% Cl) \\
\hline \multicolumn{2}{|l|}{ Maternal Smoking } \\
\hline Yes & $1.40(1.07,1.83)$ \\
\hline No & 1.00 \\
\hline \multicolumn{2}{|l|}{ Infant's Sex } \\
\hline Male & $1.89(1.54,2.32)$ \\
\hline Female & 1.00 \\
\hline Maternal age (continuous) & $0.97(0.95,0.99)$ \\
\hline \multicolumn{2}{|l|}{ Maternal race/ethnicity } \\
\hline White, non-Hispanic & 1.00 \\
\hline Black, non-Hispanic & $0.67(0.51,0.87)$ \\
\hline Hispanic & $0.91(0.65,1.27)$ \\
\hline Other & $0.66(0.35,1.23)$ \\
\hline \multicolumn{2}{|l|}{ Timing of prenatal care initiation } \\
\hline Adequate ( $1^{\text {st }}$ trimester $)$ & 1.00 \\
\hline Late (after $1^{\text {st }}$ trimester or none) & $0.70(0.51,0.96)$ \\
\hline
\end{tabular}

N.C. Department of Health and Human Services

\section{Conclusions}

The findings of this study are consistent with the hypothesis that maternal smoking during pregnancy confers an increased risk of an infant being born with clubfoot. More research is necessary to elucidate the biologic mechanisms by which maternal smoking affects a developing fetus, and the combined role that genetics and environment play in this process. This study, in conjunction with the results of previous investigations, underscores the need to educate women of childbearing age of the array of adverse outcomes that may affect the infant whose mother smokes during pregnancy. These include birth defects as well as low birth weight and sudden infant death syndrome (SIDS).

\section{References}

1. Wynne-Davies R. 1964. Family studies and the cause of congenital clubfoot. J Bone Joint Surg Am 46:445-452.

2. Ching GH, Chung CS, Nemecheck RW. 1969. Genetic and epidemiological studies of clubfoot in Hawaii: ascertainment and incidence. Am J Hum Genet 21:566-580.

3. Moorthi RN, Hashmi SS, Langois P, Canfield M, Waller DK, Hecht JT. 2005. Idiopathic talipes equinovarus (ITEV) (clubfeet) in Texas. Am J Med Genet 132A:376-380.

4. Alberman ED. 1965. The causes of congenital club foot. Arch Dis Child 40:548-554.

5. Cartlidge I. 1984. Observations on the epidemiology of clubfoot in Polynesian and Caucasian populations. J Med Genet 21:290-292.

6. Kite JH. Etiology of clubfoot. 1964. In: Kite JH, editor. The clubfoot. New York: Grune \& Stratton. p. 3-12.

7. Hootnick DR, Packard DR, Levinsohn EM, Wladis A. 1994. A vascular hypothesis for the etiology of clubfoot. In: The clubfoot. New York: Springer-Verlag.

8. Martin RF, Milo-Manson G, McComas A, Levin S. 1994. Neurogenic origin of talipes equinovarus. In: Simon G, editor. The clubfoot: the present and a view of the future. New York: Springer-Verlag. 39-41.

9. Honein MA, Paulozzi LJ, Moore CA. 2000. Family history, maternal smoking, and clubfoot: 
an indication of a gene-environment interaction. Am J Epidemiol 152:658-665.

10. Wynne-Davies R. 1972. Genetic and environmental factors in the etiology of talipes equinovarus. Clin Orthop 84:9-13.

11. Skelly AC, Holt VL, Mosca VS, Alderman BW. 2002. Talipes equinovarus and maternal smoking: a population-based case-control study in Washington state. Teratology 66:91-100.

12. Shiono PH, Klebanoff MA, Berendes HW. 1986. Congenital malformations and maternal smoking during pregnancy. Teratology 34:65-71.
For more information about this publication, contact:

Kathryn Dickinson at (919) 715-0263

e-mail: Kathryn.Dickinson@ncmail.net

For a list of other publications by the

State Center for Health Statistics call:

(919) 733-4728

or check the website at: www.schs.state.nc.us/SCHS/

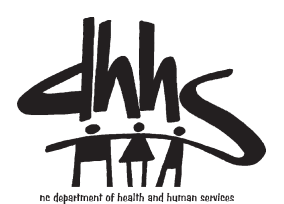

State of North Carolina

Michael F. Easley, Governor

Department of Health and Human Services

Carmen Hooker Odom, Secretary

Division of Public Health

Leah Devlin, DDS, Director

Chronic Disease and Injury Section

Marcus Plescia, M.D., M.P.H., Section Chief

State Center for Health Statistics

Paul A. Buescher, PhD, Director

www.ncdhhs.gov

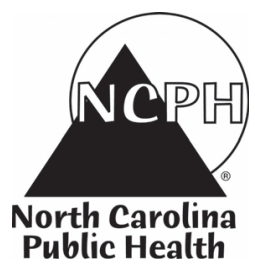

N.C. DHHS is an equal opportunity employer and provider.

Department of Health and Human Services

State Center for Health Statistics

1908 Mail Service Center

Raleigh, NC 27699-1908

(919) 733-4728 